\title{
LUT
}

University

Managing continuous innovation through performance measurement

Saunila Minna

This is a Post-print

version of a publication

published by Emerald Publishing

in Competitiveness Review

DOI: $\quad 10.1108 / C R-03-2015-0014$

Copyright of the original publication: @ Emerald Publishing 2017

Please cite the publication as follows:

Saunila, M. (2017). Managing continuous innovation through performance measurement. Competitiveness Review, vol. 27, issue 2. pp. 179-190. DOI: 10.1108/CR-03-2015-0014

This is a parallel published version of an original publication. This version can differ from the original published article. 
Saunila, M. (2017). Managing continuous innovation through performance measurement. Competitiveness Review: An International Business Journal, 27(2), 179-190.

\section{MANAGING CONTINUOUS INNOVATION THROUGH PERFORMANCE MEASUREMENT}

\section{Structured Abstract:}

Purpose: To define measures that small and medium-sized enterprises (SMEs) can use for evaluating continuous innovation and to analyze types of SMEs, according to the innovation measures they use and their characteristics in terms of size and operational and financial performance.

Design/methodology/approach: The data were gathered with the help of a structured survey questionnaire from a cross-section of firms in both the manufacturing and service sectors in Finland. The data were analyzed in terms of factor and cluster analyses.

Findings: Three measures of continuous innovation and three types of SMEs were defined based on their continuous innovation measures. It was found that firms using all three types of innovation measures also register above-average financial and operational performance compared to those that do not.

Originality/value: This study attempts to improve the precision of performance measurement and the management of continuous innovation in firms by expanding and refining existing measurement guidelines and principles. In particular, this work approaches the subject of continuous innovation measurement from the standpoint of SMEs.

Keywords: Continuous innovation, Performance measurement, Innovation measurement, Firm performance, SME, Structured survey 
Saunila, M. (2017). Managing continuous innovation through performance measurement. Competitiveness Review: An International Business Journal, 27(2), 179-190.

\section{INTRODUCTION}

Small and medium-sized enterprises (SMEs) are important sources of innovation for the future (Bititci et al., 2012). Performance is viewed as a process that enables better management and sustenance of SMEs (Ates et al., 2013), and innovation is a key driver of SME performance. Continuous innovation - defined as "the ongoing interaction between operations, incremental improvement, learning and radical innovation aimed at effectively combining operational effectiveness and strategic flexibility" (Boer and Gertsen, 2003) - is a factor that can result in superior firm performance. Performance measurement within organizations identifies areas of a business that need attention and improvement. Similarly, measures of continuous innovation are needed to ensure that the existing systems and processes always allow for ongoing improvement and innovation (Soosay and Chapman, 2006).

The measurement of innovation continues to remain a research challenge that is widely discussed (Bititci et al., 2012). In the field of performance management, innovation has been considered one of the main business processes of an organization. Although it has long been acknowledged that continuous improvement in processes and product capabilities is critical for long-term success (Kaplan and Norton, 1996), the role of continuous innovation in performance measurement has not received much attention until recently. The majority of studies on performance measurement use R\&D expenditure as the principal measure of innovation. However, in the case of SMEs, fewer resources are directed toward $R \& D$, which limits the use of such a measure as an innovation indicator. Further, $R \& D$ is just one possible way of promoting innovation. The idea of continuous innovation is that it is integrated into one's daily work and requires new ways of working, as well as processes and activities supporting it. Performance management and measurement in SMEs seem to be limited to the study of SMEs from more traditional perspectives (Bititci et al., 2012). In particular, research related to the performance management of innovation is scarce. Although the performance measurement of innovation is recognized as difficult, it is vital for driving continuous innovation (Adams et al. 2006; Carpinetti et al., 2007).

This study attempts to improve the precision of performance measurement and the management of continuous innovation by expanding and refining existing measurement guidelines and principles. Although earlier studies (c.f., Soosay and Chapman, 2006) have investigated the measurement of continuous innovation, there is a lack of SME-specific approaches to the subject. Resource-constrained SMEs (Garengo et al., 2005) do not require as many measures of performance or continuous innovation as large companies. Thus, there is a growing need to identify the determinants of performance measurement and the management of continuous innovation that appropriate for SMEs. Accordingly, the objectives of this study are to define (1) 
Saunila, M. (2017). Managing continuous innovation through performance measurement. Competitiveness Review: An International Business Journal, 27(2), 179-190.

measures that SMEs can use when assessing continuous innovation and (2) types of SMEs, based on these measures, for managing performance through continuous innovation.

This paper is organized as follows. The literature review discusses work from the past that is relevant to the present study. This is followed by the research methodology, which provides details about the data collection procedure. Next, the results of the data analysis are presented. Finally, the conclusions from the research are summarized.

\section{LITERATURE REVIEW}

\subsection{MANAGING CONTINUOUS INNOVATION THROUGH MEASURES}

Numerous scholars have suggested that the competitiveness of SMEs can be increased through innovation - by defining innovation more consistently and paying attention to innovation measurement (Gorton, 2000; McAdam and Keogh, 2004). Neely et al. (2000) have concluded that measurement must not be seen as obtrusive or contradictory to innovation. In fact, when conducted properly, it can boost innovation development. Continuous innovation, in particular, should be actively managed and measured, and performance measurement plays a very important role in this. The impact of improvement and change actions should be monitored to evaluate the progress in achieving continuous innovation and in achieving economic and social results (Carpinetti et al., 2007).

It is important to measure innovation for at least two reasons. Measurement information serves as the basis for making decisions on innovation activities. Second, measurement assists in defining goals and planning the actions to achieve these goals (Neely and Hii, 1998; Muller et al., 2005; Skarzynski and Gibson, 2008). During the transitional process of developing an innovation, the measures should be dynamic and changeable and continually reviewed and developed (Neely et al., 2000; McAdam and Keogh, 2004). Given the diversity within innovation, measuring innovation must be given more strategic and operational importance, and a wide range of measures should be adopted (McAdam and Keogh, 2004). The different areas of assessment should not be viewed as divergent or contradictory, but as supplementary. Key aspects to be measured in order to facilitate continuous innovation are the outcomes of the strategies, action plans, systems, and processes (Soosay and Chapman, 2006).

The appropriate control and performance measurement approaches can significantly benefit the management of innovation (Schentler et al., 2010). This is because performance measurement within organizations identifies areas of a business that need attention and improvement (Soosay and Chapman, 2006). In other words, appropriate performance measures can contribute to a 
Saunila, M. (2017). Managing continuous innovation through performance measurement. Competitiveness Review: An International Business Journal, 27(2), 179-190.

significantly better understanding of innovation. To be effective, any measurement system should focus on the critical success factors for the particular business and its sector of activity (Birchall et al., 2011). Tidd et al. (2001) argue that innovation measurement must focus on those innovative activities of the firm that ensure its success in the marketplace. Evaluating innovation accurately and finding the key factors influencing innovation are essential (Shan and Zhang, 2009). The innovation measurement literature highlights the importance of measuring a wide number of factors and phenomena, such as innovation strategy, ideas and ideation, customer and market, organizational learning and knowledge management tools, and organizational culture and leadership (Adams et al., 2006; Crossan and Apaydin, 2010; Saunila and Ukko, 2012).

\subsection{LACK OF COMPREHENSIVE MEASUREMENT CATEGORIES}

Today, the scope of performance measurement has widened to include identifying innovation opportunities and providing information on specific industries (Davila, 2012). Research has approached innovation performance measurement from two perspectives: the measurement of R\&D (cf., Alegre et al., 2006; Chiesa and Frattini, 2009; Chiesa et al., 2009; Lazzarotti et al., 2011; Cruz-Cázares et al., 2013) and the measurement of technological innovation capability (cf. Capaldo et al., 2003). In addition, conceptual models have discussed the essential elements of innovation that should be measured (cf. Muller et al., 2005; Adams et al., 2006; Saunila and Ukko, 2012). However, indicators of innovation in SMEs have often been limited to production-oriented measures (Freel, 2000). At the firm level, these include the effectiveness of R\&D investment, the effectiveness of the new product development process, the effectiveness of the management of change, and the degree to which enablers of innovation are present and, hence, the future secured (Birchall et al., 2011). R\&D expenditure has been traditionally used as the principal innovation measure, though it suffers from several shortcomings. In R\&D, high performance is considered the successful transformation of research efforts into new products, and measurement mostly focuses on outputs such as the number of patents generated (Godener and Söderquist, 2004). However, such a measure cannot capture the state of innovation in SMEs, where fewer resources are invested in R\&D. This has resulted in a new stream of research that studies the effect of innovation on firm performance by analyzing the triggers and the paths that companies follow to achieve a structure that is increasingly capable of continuous problem solving and innovation (Armbruster et al., 2008; Hashi and Stojcic, 2013). When managing innovation, it is no longer wise to consider innovation as a linear process by which resources are channeled at one end and a new product or process emerges at another (Adams et al., 2006).

According to Birchall et al. (2011), it is necessary to understand the nature of the innovation in order to align measurement and generate more actionable outcomes from measurement. It is also 
Saunila, M. (2017). Managing continuous innovation through performance measurement. Competitiveness Review: An International Business Journal, 27(2), 179-190.

necessary to define the areas requiring measurement in order to support decision makers in the design and selection of appropriate measures (Birchall et al., 2011).

Four types of innovation measures have been proposed in the literature: input, process, output, and outcome. Input measurement captures the resources allocated to innovation, such as personnel, funds, equipment, and ideas (c.f., Skarzynski and Gibson, 2008; Janssen et al., 2011). Process measurement aims to clarify what happens between the inputs and outputs of innovation (Carayannis and Provance, 2008). Process measures can include the achievement of objectives in terms of time, cost, and quality. Output measurement assesses the direct results of innovation activities (i.e., new products or generated knowledge). Outcome measurement demonstrates longterm results in terms of success in the marketplace (i.e., revenue, profit, market share, and customer satisfaction) (Janssen et al., 2011). Thus, these outcomes reflect the performance implications of innovation. According to Adams et al. (2006), innovation measurement tends to focus on output measurement. However, the comprehensive measurement of innovation requires the consideration of input, process, and output measurement simultaneously (Carayannis and Provance, 2008). The measurement scheme must be multidimensional (Dewangan and Godse, 2014). Saunila and Ukko (2012) have classified innovation capability into three elements - innovation potential, innovation processes, and the results of innovation activities - all of which have to be measured to acquire a comprehensive picture of innovation. It is not enough to know how many new innovative processes, actions, or products have been generated if there is no understanding of their drivers (Saunila and Ukko, 2012), because they are needed in order to communicate how the implications are to be achieved. A wide range of innovation measures have been suggested because managing innovation requires a variety of information that a single or a few measures cannot provide (McAdam and Keogh, 2004; Carayannis and Provance, 2008).

Another type of measurement is to highlight the capability or success factors to create innovations. For example, Perdomo-Ortiz et al. (2006) use the term business innovation capability to describe the critical success factors of innovation processes. These critical factors can be interpreted as business innovation capability dimensions, and the capability can be measured with the factors. According to the earlier literature, these factors include, for example, leadership practices, employees' ideas, work well-being and expertise, external sources for information, functionality of internal processes, and the development of action paths related to development (cf., Muller et al., 2005; Adams et al., 2006; Carayannis and Provance, 2008; Crossan and Apaydin, 2010; Saunila and Ukko, 2012).

The main problem with measuring innovation stems from the fact that it is a multidimensional phenomenon. Further, innovation is context-specific, which impedes the comparability of the data (Neely and Hii, 1998). Current measures predict results but not the reasons for the results. They 
Saunila, M. (2017). Managing continuous innovation through performance measurement. Competitiveness Review: An International Business Journal, 27(2), 179-190.

actually measure innovation performance rather than the ability for continuous innovation. These measures oversimplify the complex nature of the sources of innovation (Neely and Hii, 1998). The challenge, thus, is to identify techniques that intuitively predict the measures of innovation performance, and in the context of SMEs, such measures have not been clearly defined.

\section{RESEARCH METHODOLOGY}

\subsection{ITEMS}

As there is no comprehensive scale to measure the performance of continuous innovation, the scales to be used were developed first. For this study, the unit of analysis was a respondent's perceptions of performance measurement of continuous innovation at an organizational level. Subjective measures were utilized because studies have shown high correlation and concurrent validity between objective and subjective measurements (e.g., Dess and Robinson, 1984; Venkatraman and Ramanujan, 1987). On the basis of the literature review, nine items of continuous innovation performance measurement were operationalized. The selected items and their backgrounds are presented in Table 1. For each of the nine items, the respondents were asked to indicate their opinions on a Likert-type scale ranging from 1 (strongly disagree) to 5 (strongly agree). A neutral response "neither disagree nor agree" was included to reduce uninformed responses. Four background variables-revenue (objective), number of employees (objective), financial performance (subjective), and operational performance (subjective)—were also entered in the survey.

The scale contained two self-reported subjective measures of firm performance (financial performance and operational performance over the past three years). Objective performance measures were not used for multiple reasons: respondents may not have accurate information to provide about performance measures; finding the actual numerical value would have required extra work for the respondent; and the respondent may also be more reluctant to provide objective performance information than perceptual, which also advocates the use of perceptual measures. Indeed, operational performance reflects outcomes that do not necessarily exist in the comparable (for example, between industries) or directly observable sense. In such cases, objective measures are clearly inappropriate. By using subjective data, the aim was to ensure comparability between different kinds of firms.

Construct validity (i.e., whether or not the items truly measure what they intend to measure) of the scales was assessed by content validity, criterion validity, and discriminant validity (Hair et al., 2010). Content validity was ensured by grounding the scale on a strong theoretical basis. To ensure the appropriateness of each item, the items were reviewed and revised with a group of researchers. 
Saunila, M. (2017). Managing continuous innovation through performance measurement. Competitiveness Review: An International Business Journal, 27(2), 179-190.

Criterion validity was assessed through correlation analyses, which showed that the constructs behaved in a credible manner. Discriminant validity was assessed through exploratory factor analyses, which supported the unidimensionality of the scales. Further, the lack of significant cross-loadings supported discriminant validity. In addition to validity, the reliability of the scale was assessed by following the correct procedure for performing statistical analysis: from data collection to interpretation.

Table 1. Measurement items

\begin{tabular}{|c|c|c|}
\hline Item & Relevance to measuring continuous innovation & Reference \\
\hline $\begin{array}{l}1 \text { Our company has measures for evaluating } \\
\text { development }\end{array}$ & $\begin{array}{l}\text { Overall development activities are being } \\
\text { measured }\end{array}$ & c.f., Crossan and Apaydin, 2010 \\
\hline $\begin{array}{l}2 \text { Exploitation of external knowledge } \\
\text { (customers, competitors, etc.) is evaluated or } \\
\text { measured in our company }\end{array}$ & $\begin{array}{l}\text { Measures for assessing external links (c.f., } \\
\text { collaboration with suppliers and customers) exist }\end{array}$ & $\begin{array}{l}\text { c.f., Capaldo et al., 2003; McAdam and } \\
\text { Keogh, 2004; Crossan and Apaydin, } \\
\text { 2010; Saunila and Ukko, } 2012\end{array}$ \\
\hline $\begin{array}{l}3 \text { The functionality of internal processes is } \\
\text { evaluated or measured in our company }\end{array}$ & $\begin{array}{l}\text { Internal processes and structures that support and } \\
\text { reflect continuous innovation are measured }\end{array}$ & $\begin{array}{l}\text { c.f., McAdam and Keogh, 2004; Adams } \\
\text { et al., 2006; Carayannis and Provance, } \\
\text { 2008; Saunila and Ukko, } 2012\end{array}$ \\
\hline $\begin{array}{l}4 \text { The development of action paths is } \\
\text { evaluated or measured in our company }\end{array}$ & $\begin{array}{l}\text { There are measures of ways of communication } \\
\text { and collaboration }\end{array}$ & $\begin{array}{l}\text { c.f., Adams et al., 2006; Carayannis and } \\
\text { Provance, } 2008\end{array}$ \\
\hline $\begin{array}{l}5 \text { Leadership practices are evaluated or } \\
\text { measured in our company }\end{array}$ & $\begin{array}{l}\text { Leaders' orientation toward continuous } \\
\text { innovation is measured }\end{array}$ & $\begin{array}{l}\text { c.f., Muller et al., 2005; Adams et al., } \\
\text { 2006; Crossan and Apaydin, 2010; } \\
\text { Saunila and Ukko, } 2012\end{array}$ \\
\hline $\begin{array}{l}6 \text { Employees' ideas are evaluated or } \\
\text { measured in our company }\end{array}$ & Measures of idea generation approaches exist & $\begin{array}{l}\text { c.f., McAdam and Keogh, 2004; Muller } \\
\text { et al., 2005; Adams et al., 2006; Crossan } \\
\text { and Apaydin, } 2010\end{array}$ \\
\hline $\begin{array}{l}7 \text { Employees' work well-being is evaluated } \\
\text { or measured in our company }\end{array}$ & $\begin{array}{l}\text { Organizational well-being and climate are } \\
\text { measured }\end{array}$ & $\begin{array}{l}\text { c.f., Crossan and Apaydin, 2010; Adams } \\
\text { et al., } 2006\end{array}$ \\
\hline $\begin{array}{l}8 \text { Employees' expertise is evaluated or } \\
\text { measured in our company }\end{array}$ & $\begin{array}{l}\text { Measures linked to employees' development and } \\
\text { skills exist }\end{array}$ & $\begin{array}{l}\text { c.f., Muller et al., 2005; Adams et al., } \\
\text { 2006; Crossan and Apaydin, 2010; } \\
\text { Saunila and Ukko, } 2012\end{array}$ \\
\hline $\begin{array}{l}9 \text { Measurement information is used for } \\
\text { developing company actions and operations }\end{array}$ & $\begin{array}{l}\text { Measurement is used to identify areas of a } \\
\text { business that need attention and improvement }\end{array}$ & $\begin{array}{l}\text { c.f., Soosay and Chapman, 2006; } \\
\text { Saunila and Ukko, } 2012\end{array}$ \\
\hline
\end{tabular}

\subsection{SAMPLE AND DATA GATHERING}

A quantitative approach was used in this study. SMEs were chosen as the target group because of their significant role in the Finnish economy. Finland has a little over 320,000 enterprises, of which 99.8\% are SMEs. Of all private-sector employees, as many as 63\% work for SMEs. These enterprises generate about $50 \%$ of the combined turnover of all Finnish businesses. SMEs are responsible for more than $13 \%$ of Finland's export revenue (The Federation of Finnish Enterprises).

The data were gathered with the help of a structured survey questionnaire distributed among a cross-section of SMEs from both manufacturing and service sectors in Finland. The initial sample consisted of 2,400 SMEs, employing 10-249 persons, with a revenue of less than 50 million euros. The sample firms were randomly selected as long as they satisfied the following conditions. First, 
Saunila, M. (2017). Managing continuous innovation through performance measurement. Competitiveness Review: An International Business Journal, 27(2), 179-190.

the firms had to have more than 10 employees to ensure that the routines and processes of innovation performance measurement were present. Second, because Neely and Hii (1998) argue that data collection from only the top executives of the organizations does not provide a true measure of the entire organization's behavior toward innovation, the survey was sent to both management representatives and employees to cover both perspectives in the study. Third, a valid e-mail address was needed for each respondent because the survey was web-based. The first email reached 4,050 respondents. One week after the survey was first mailed, reminder surveys were sent out. Three follow-up e-mails (each one week after the previous reminder) were sent to those who had not yet responded. This process resulted in 286 responses, which equals a response rate of $7.6 \%$.

The potential for nonresponse bias was assessed by comparing the means of the responses in the last quartile to those in the first three. It was assumed that those who were among the last to respond most closely resembled the nonrespondents (Armstrong and Overton, 1977). The analysis of variance test revealed no significant difference (at the 5\% significance level) in the responses between the four groups regarding the constructs. Thus, nonresponse bias was not considered a problem in this study.

Other biases were also assessed to ensure the representativeness of the sample. The sample was selected randomly to minimize both the voluntary response bias and the under-coverage bias. Both procedural and statistical remedies were used to minimize the potential effects of the common method bias, as suggested by Podsakoff et al. (2003). Respondents were allowed to answer anonymously. This way, the respondents are less likely to edit their responses for social desirability. Another way of reducing common method biases is careful construction of the items themselves. This technique was used as presented in the earlier section. In addition to procedural techniques, statistical analyses were conducted. Harman's single-factor test was used to statistically address the issue of common method bias. All the variables used in the study were loaded into exploratory factor analysis, and the un-rotated factor solution was analyzed. Either of the criteria of the technique (i.e., emergence of a single factor from the factor analysis or one general factor accounting for the majority of the covariance of the measures) was met. Thus, no common method variance exists (Podsakoff et al., 2003).

\section{RESULTS}

To classify the continuous innovation measures into groups, factor analysis was conducted. The Kaiser-Meyer-Olkin (KMO) test was used to analyze the sample adequacy for the variables. The overall KMO value was 0.844 , which is above the acceptable value proposed for this type of analysis. Next, principal component analysis with varimax rotation was used to extract relevant 
Saunila, M. (2017). Managing continuous innovation through performance measurement. Competitiveness Review: An International Business Journal, 27(2), 179-190.

factors of continuous innovation measurement. According to Hair et al. (2010), factor loadings of 0.50 or greater are considered practically significant. Thus, only the loadings above 0.50 were selected. Communalities above 0.5 were accepted. From the factor analysis procedure, three factors (based on an eigenvalue greater than 1) were obtained (see Table 2). This solution explained $67.28 \%$ of the total variance. The three factors of performance measurement of continuous innovation extracted are as follows.

Table 2. Factor analysis results

\begin{tabular}{lcccc}
\hline & Factor 3 & Factor 2 & Factor 1 & Comm. \\
\cline { 2 - 4 } Cronbach's alpha & $\mathbf{0 . 7 5 2}$ & $\mathbf{0 . 7 9 7}$ & $\mathbf{0 . 6 6 5}$ & 0.574 \\
\hline 7 & 0.732 & & & 0.679 \\
8 & 0.804 & & & 0.743 \\
9 & 0.771 & & 0.800 \\
3 & & 0.844 & 0.799 \\
4 & & 0.846 & & 0.579 \\
5 & & 0.562 & 0.688 & 0.590 \\
1 & & & 0.853 & 0.765 \\
2 & & & 0.596 & 0.527 \\
6 & & & 1.856 & \\
\hline Eigenvalue & 2.182 & 2.018 & 6.618 & \\
\% of variance explained & 24.244 & 22.418 & & \\
Cumulative & 24.244 & 46.662 & & \\
\hline
\end{tabular}

Principal component analysis - varimax rotation

KMO measure of sampling adequacy 0.844

Personnel-driven measures (F3): The first factor comprises three items: "Employees' work wellbeing is evaluated or measured in our company," "Employees' expertise is evaluated or measured in our company," and "Measurement information is used for developing company actions and operations." This first factor includes a set of items directly or indirectly related to personnel issues that should be taken into account when measuring continuous innovation. This includes both personnel's work well-being and expertise. The factor explains $24.2 \%$ of the variance.

Internal process-driven measures (F2): The second factor consists of three items: "The functionality of internal processes is evaluated or measured in our company," "The development of action paths is evaluated or measured in our company," and "Leadership practices are evaluated or measured in our company." This factor includes items directly related to the measurement of internal processes and other internal issues. These also relate to ways of action and leadership practices that affect the functionality of innovation activities. The factor explains $22.4 \%$ of the variance.

Ideation-driven measures (F1): The third factor also comprises three items: "Our company has measures for evaluating development," "Exploitation of external knowledge (customers, competitors, etc.) is evaluated or measured in our company," and "Employees' ideas are evaluated 
Saunila, M. (2017). Managing continuous innovation through performance measurement. Competitiveness Review: An International Business Journal, 27(2), 179-190.

or measured in our company." This factor includes the items that represent the traditional measures of innovation. The factor reflects both the measures of development and ideations, as well as the behavior of exploiting external information. The factor explains $20.6 \%$ of the variance.

Cronbach's alpha test was used to test the reliability of the construct. The alpha value of all three factors, as shown in Table 2, is greater than 0.60 . The overall reliability of the construct is, therefore, supported.

With clustering, the aim was to determine the categories of SMEs that could be derived based on their performance measurement of continuous innovation. The K-Means clustering method was chosen because it is better suited for grouping based on conceptual issues than hierarchical clustering. A good option for clustering is to employ the factor analysis results and use the sum measures of the factors because their intercorrelations are usually zero. Thus, the variables were continuous innovation performance measures developed on the basis of factor analysis: (1) ideation measures, (2) internal measures, and (3) personnel measures. Clusters were profiled and named based on SME activity in performance measurement of continuous innovation (Table 3) and background variables (Table 4).

Table 3. Means of the sum measures of continuous innovation performance in each cluster

\begin{tabular}{lcccccccc}
\hline & \multicolumn{9}{c}{ Mean } & & F & (df) & p \\
\cline { 2 - 5 } & Overall & Cluster 1 & Cluster 2 & Cluster 3 & & & & \\
\hline Ideation measures & 2,95 & 3,82 & 2,20 & 2,72 & & 191,772 & 2,000 &, 000 \\
Internal measures & 3,16 & 3,96 & 1,98 & 3,20 & & 279,396 & 2,000 &, 000 \\
Personnel measures & 3,47 & 4,05 & 2,45 & 3,57 & 135,068 & 2,000 &, 000 \\
\hline
\end{tabular}

Table 4. Distribution of the responses in each cluster

\begin{tabular}{|c|c|c|c|c|c|c|c|c|}
\hline & \multicolumn{2}{|c|}{ All $(n=274)$} & \multicolumn{2}{|c|}{ Cluster $1(n=85)$} & \multicolumn{2}{|c|}{ Cluster $2(n=66)$} & \multicolumn{2}{|c|}{ Cluster $3(n=123)$} \\
\hline & No & $\%$ & No & $\%$ & No & $\%$ & No & $\%$ \\
\hline \multicolumn{9}{|l|}{ Revenue } \\
\hline Under 5 & 123 & 45 & 34 & 40 & 32 & 48 & 7 & 46 \\
\hline Under 10 & 71 & 26 & 21 & 25 & 16 & 24 & 34 & 28 \\
\hline 10 and over & 80 & 29 & 30 & 35 & 18 & 27 & 32 & 26 \\
\hline \multicolumn{9}{|c|}{ No of employees } \\
\hline Under 20 & 71 & 26 & 19 & 22 & 19 & 29 & 33 & 27 \\
\hline Under 50 & 127 & 46 & 37 & 44 & 32 & 48 & 58 & 47 \\
\hline 50 and over & 76 & 28 & 29 & 34 & 15 & 23 & 32 & 26 \\
\hline \multicolumn{9}{|c|}{ Financial performance } \\
\hline Weak & 27 & 10 & 6 & 7 & 12 & 18 & 9 & 7 \\
\hline Satisfactory & 80 & 29 & 28 & 33 & 15 & 23 & 37 & 30 \\
\hline Good & 120 & 44 & 35 & 41 & 30 & 45 & 55 & 45 \\
\hline Excellent & 47 & 17 & 16 & 19 & 9 & 14 & 22 & 18 \\
\hline \multicolumn{9}{|c|}{ Operational performance } \\
\hline Weak & 10 & 4 & 2 & 2 & 6 & 9 & 2 & 2 \\
\hline Satisfactory & 96 & 35 & 25 & 29 & 24 & 36 & 47 & 38 \\
\hline Good & 136 & 50 & 44 & 52 & 27 & 41 & 65 & 53 \\
\hline Excellent & 30 & 11 & 14 & 16 & 7 & 11 & 9 & 7 \\
\hline
\end{tabular}


Saunila, M. (2017). Managing continuous innovation through performance measurement. Competitiveness Review: An International Business Journal, 27(2), 179-190.

\begin{tabular}{lllllllll}
\hline No response & 2 & 1 & 0 & 0 & 2 & 3 & 0 & 0 \\
\hline
\end{tabular}

Integrated measurers. Cluster 1 includes $31 \%$ of the companies. The first cluster includes SMEs that have means higher than the average in all three factors of continuous innovation performance measures (ideation measures, internal measures, and personnel measures). These companies have access to a variety of continuous innovation measures, and they utilize them in developing innovation. This cluster consists mostly of medium-sized companies whose operational and financial performance is better than the average.

Traditional measurers. Cluster 2 accounts for $24 \%$ of the companies. Their scores on continuous innovation performance measures are less than average and less than those of the other groups. The use of continuous innovation measures is modest in these companies. The majority of the companies in this cluster are small, and their financial and operational performance is weaker than the average and that of the other groups.

Internal measurers. Cluster 3 includes $45 \%$ of the companies. These companies use internal measures and personnel measures, but their use of ideation measures is better than the average. This cluster includes an equal number of small- and medium-sized companies. Their financial performance is better than the average, but operationally, they are weaker than average.

\section{CONCLUSIONS}

The objective of this study was to define measures that SMEs could utilize when evaluating continuous innovation and for the management of continuous innovation performance. Thus, this work contributes to current knowledge on performance measurement and the management of continuous innovation in SMEs.

In terms of a theoretical contribution, the paper contains a comprehensive description of the measures of continuous innovation in an SME context. Three categories of continuous innovation measures have been identified. This study shows that, in addition to traditional ideation measures, personnel- and internal process-driven measures can be utilized in continuous innovation performance measurement.

The study also clarifies how SMEs can be categorized according to their use of continuous innovation measures. Here, SMEs have been grouped into integrated, internal, and traditional measurers on the basis of their approach to continuous innovation performance measurement. According to Carpinetti et al. (2007), performance measurement plays a very important role in the 
Saunila, M. (2017). Managing continuous innovation through performance measurement. Competitiveness Review: An International Business Journal, 27(2), 179-190.

continuous innovation management process. They explain that the impact of improvement and change actions should be monitored to evaluate the progress in achieving continuous innovation and in achieving economic and social results. This view is also supported by the results of this study: integrated measurers perform better than the clusters in terms of financial and operational performance. In these companies, all continuous innovation measurement categories were well represented. This confirms that no single measurement category is more important than the others; instead, a variety of continuous innovation performance measures should be adopted. SMEs have inherent drawbacks related to performance measurement when compared to larger firms. This also seems to be the case when considering continuous innovation performance measurement. The majority of the traditional measurers were small firms, whereas the majority of the integrated measurers were medium-sized firms.

\section{Managerial implications}

In terms of practical contribution, the study increases one's understanding of performance measurement of continuous innovation. Using the results of this study, practitioners can improve their methods of continuous innovation through performance measurement by better evaluating various situations. The results of this study highlight the fact that continuous innovation should be measured, and all three categories of continuous innovation performance measurement should be covered. SME managers can exploit these guidelines when developing measures of monitoring continuous innovation.

\section{Limitations and further research}

There are limitations of this research. Given that the study focuses on SMEs, the results are not generalizable to large firms. Also, because micro firms were excluded from the sample, these results cannot be generalized to micro firms. The results are based on data from a single country, and the specific country characteristics should be taken into account when applying the results in practice or in further studies. Another limitation of the work is the low response rate. It is likely that the challenging subject matter of the survey affected the response rate. Attempts were made to avoid this problem of low response rate through the careful construction of both the cover letter and the survey itself. The respondents were given the chance to bypass an item if they did not have enough information to respond. Also, nonresponse bias was checked and did not present a problem. However, given the low response rate, the results should be handled circumspectly. There are also some limitations of the analyses used. There is reported to be a problem of sample size in factor analysis, but a limit of 100 responses is common (e.g., Hair et al., 2010). Thus, the number of responses of the current study is acceptable. Further, factor analysis cannot identify causality, 
Saunila, M. (2017). Managing continuous innovation through performance measurement. Competitiveness Review: An International Business Journal, 27(2), 179-190.

which is a limitation of the study. The generalizability of cluster analysis results is limited only to the examined cases. Thus, the results of cluster analysis should be handled circumspectly.

In conclusion, this study presents some interesting findings that can serve as a good starting point for further studies. First, as this research has been mainly quantitative and conceptual, it needs to be complemented by qualitative research, which aims to provide insights into performance measurement of continuous innovation. Second, other qualitative studies are needed to formulate performance measures for identified measurement categories and firm performance so causal relationships can be identified. It has been concluded that the consequences of performance measurement depend on the way in which it is used. Therefore, more research is needed to capture the linkage between performance measurement of continuous innovation and firm performance. These issues can be tackled, for example, through in-depth case studies that facilitate a deeper understanding of the mechanisms involved. In addition, it would be interesting to study the effect of continuous innovation on sales growth and profit growth with large samples.

\section{REFERENCES}

Adams, R., Bessant, J. and Phelps, R. (2006) Innovation management measurement: A review, International Journal of Management Reviews, Vol. 8 No. 1, pp. 21-47.

Alegre, J., Lapiedra, R. and Chiva, R. (2006) A measurement scale for product innovation performance, European Journal of Innovation Management, Vol. 9 Iss. 4, pp. 333-346

Armbruster, H., Bikfalvi, A., Kinkel, S. and Lay, G. (2008) Organizational innovation: The challenge of measuring non-technical innovation in large-scale surveys, Technovation. Vol. 28 Iss. 10, pp. 644-657.

Armstrong, J.S. and Overton, T.S. (1977) Estimating non-response bias in mail surveys, Journal of Marketing Research, Vol. 14, No. 3, pp. 396-402.

Ates, A., Garengo. P., Cocca, P. and Bititci, U. (2013) The development of SME managerial practice for effective performance management, Journal of Small Business and Enterprise Development, Vol. 20 No. 1, pp. 28-54.

Birchall, D., Chanaron, J.J., Tovstiga, G. and Hillenbrand, C. (2011) Innovation performance measurement: current practices, issues and management challenges, International Journal of Technology Management, Vol. 56, No. 1, pp. 1-20. 
Saunila, M. (2017). Managing continuous innovation through performance measurement. Competitiveness Review: An International Business Journal, 27(2), 179-190.

Birchall, D.W., Tovstiga, G., Morrison, M. and Gaule, A. (2004) Innovation Performance Measurement - Striking the Right Balance, Grist, London.

Bititci, U., Garengo, P., Dörfler, V. and Nudurupati, S. (2012) Performance Measurement: Challenges for Tomorrow, International Journal of Management Reviews, Vol. 14 No. 3, pp. 305327.

Boer, H. and Gertsen. F. (2003) From continuous improvement to continuous innovation: a (retro)(per)spective, International Journal of Technology Management, Vol. 26 No. 8, pp. 805827.

Capaldo, G., Iandoli, L., Raffa, M. and Zollo, G. (2003) The evaluation of innovation capabilities in small software firms: a methodological approach, Small Business Economics, Vol. 21 No. 4, pp. 343-354.

Carayannis, E.G. and Provance, M. (2008) Measuring firm innovativeness: Towards a composite innovation index built on firm innovative posture, propensity and performance attributes, International Journal of Innovation and Regional Development, Vol. 1, No. 1, pp. 90-107.

Carpinetti, L.C.R., Gerolamo, M.C. and Cardoza Galdamez, E.V. (2007) Continuous innovation and performance management of SME clusters, Creativity and Innovation Management, Vol. 16 No. 4, pp. 376-385.

Chiesa, V. and Frattini, F. (2009) Evaluation and performance measurement of research and development: Techniques and perspectives for multi-level analysis. Edward Elgar Publishing.

Chiesa, V., Frattini, F., Lazzarotti, V. and Manzini, R. (2009) Performance measurement in R\&D: exploring the interplay between measurement objectives, dimensions of performance and contextual factors, R\&D Management, Vol. 39, Iss. 5, pp. 487-519.

Crossan, M. and Apaydin, M. (2010) A Multi-Dimensional Framework of Organizational Innovation: A Systematic Review of the Literature, Journal of Management Studies, Vol. 47, No. 6, pp. 1154-1191.

Cruz-Cázares, C., Bayona-Sáez, C. and García-Marco, T. (2013) You can’t manage right what you can't measure well: technological innovation efficiency, Research Policy, Vol. 42 Iss. 6-7, pp. 1239-1250. 
Saunila, M. (2017). Managing continuous innovation through performance measurement. Competitiveness Review: An International Business Journal, 27(2), 179-190.

Davila, A. (2012) New trends in Performance Measurement and Management control, pp.65-87, in Davila, A., Epstein, M. and Manzoni, J-F. (eds.) Performance Measurement and Management Control: Global Issues, Emerald Group Publishing Limited, 486 p.

Dess, G.G. and Robinson, R. B. (1984) Measuring organizational performance in the absence of objective measures: the case of the privately-held firm and conglomerate business unit, Strategic Management Journal, Vol. 5, No. 3, pp. 265-273.

Dewangan, V. and Godse, M. (2014) Towards a holistic enterprise innovation performance measurement system, Technovation, Vol. 34 Iss. 9, pp. 536-545

The Federation of Finnish Enterprises. Statistics of entrepreneurship. [Referenced 17.3.2016] Available: http://www.yrittajat.fi/File/37743568-32d9-43d0-be646ebd7f02309e/enterprises2013.pdf

Freel, M. (2000) Barriers to product innovation in small manufacturing firms, International Small Business Journal, Vol. 18, No. 3, pp. 60-81.

Garengo, P., Biazzo, S. and Bititci, U.S. (2005) Performance measurement systems in SMEs: a review for a research agenda, International Journal of Management Reviews, Vol. 7 No. 1, pp. 2547.

Godener, A. and Söderquist, K.E. (2004) Use and impact of performance measurement results in R\&D and NPD: an exploratory study, R\&D Management, Vol. 34 Iss. 2, pp. 191-219.

Gorton, M. (2000) Overcoming the structure - agency divide in small business research, International Journal of Entrepreneurial Behaviour and Research, Vol. 6, No. 5, pp. 276-292.

Hair, J.F., Jr., Black, W.C., Babin, B.J. and Anderson, R.E. (2010) Multivariate Data Analysis: A Global Perspective, 7th ed., Prentice-Hall, Upper Saddle River, NJ.

Hashi, I. and Stojcic, N. (2013) The impact of innovation activities on firm performance using a multi-stage model: Evidence from the Community Innovation Survey 4, Research Policy, Vol. 42 No. 2, pp. 353-366.

Janssen, S., Moeller, K. and Schlaefke, M. (2011) Using performance measures conceptually in innovation control, Journal of Management Control, Vol. 22 No. 1, pp. 107-128. 
Saunila, M. (2017). Managing continuous innovation through performance measurement. Competitiveness Review: An International Business Journal, 27(2), 179-190.

Kaplan, R.S. and Norton, D.P. (1996) The Balanced Scorecard. Translating Strategy into Action, Boston: Harvard Business School Press.

Lazzarotti, V., Manzini, R. and Mari, L. (2011) A model for R\&D performance measurement, International Journal of Production Economics, Vol. 134 Iss. 1, 212-223.

McAdam, R. and Keogh, W. (2004) Transitioning Towards Creativity and Innovation Measurement in SMEs, Creativity and Innovation Management, Vol. 13, No. 2, pp. 126-139.

Muller, A., Välikangas, L. and Merlyn, P. (2005) Metrics for innovation: guidelines for developing a customized suite of innovation metrics, Strategy and Leadership, Vol. 33 Iss. 1, pp. 37-45.

Neely, A., Mills, J., Platts, K., Richards, H., Gregory, M., Bourne, M. and Kennerley, M. (2000) Performance measurement system design: developing and testing a process-based approach, International Journal of Operations \& Production Management, Vol. 20, No. 10, pp. 1119-1145.

Neely, A. and Hii, J. (1998) Innovation and Business Performance: A Literature Review, Report produced for Government Office for the Eastern Region, Cambridge: The Judge Institute of Management Studies, University of Cambridge.

Perdomo-Ortiz, J., González-Benitoa, J. and Galende, J. (2006) Total quality management as a forerunner of business innovation capability, Technovation, Vol. 26, No. 10, pp. 1170-1185.

Podsakoff, P.M., MacKenzie, S.B., Lee, J.Y. and Podsakoff, N.P. (2003) Common method biases in behavioral research: a critical review of the literature and recommended remedies, Journal of Applied Psychology, Vol. 88, No. 5, pp. 879-903.

Saunila, M. and Ukko, J. (2012) A conceptual framework for the measurement of innovation capability and its effects, Baltic Journal of Management, Vol. 7 Iss. 4, pp. 355-375.

Schentler, P., Lindner, F. and Gleich, R. (2010) Innovation Performance Measurement, In Gerybadze, A. et al. (Eds.), Innovation and International Corporate Growth, Springer-Verlag, Berlin Heidelberg.

Shan, W. and Zhang, Q. (2009) Extension theory and its application in evaluation of independent innovation capability, Kybernetes, Vol. 38, No. 3/4, pp. 457-467. 
Saunila, M. (2017). Managing continuous innovation through performance measurement. Competitiveness Review: An International Business Journal, 27(2), 179-190.

Skarzynski, P. and Gibson, R. (2008) Innovation to the Core: A Blueprint for Transforming the Way Your Company Innovates, Harvard Business School Press, Boston.

Soosay, C.A. and Chapman, R.L. (2006) An Empirical Examination of Performance Measurement for Managing Continuous Innovation in Logistics, Knowledge and Process Management, Vol. 13 No. 3, pp 192-205.

Tidd, J., Bessant, J. and Pavitt, K. (2001) Managing Innovation: Integrating Technological, Market and Organisational Change, John Wiley, Chichester.

Venkatraman, N. and Ramanujan, V. (1987) Planning system success: A conceptualization and an operational model, Management Science, Vol. 33 No. 6, pp. 687-705. 